\title{
Serological test results of sexually transmitted diseases in patients with condyloma acuminata
}

\author{
${ }^{1}$ Department of Dermatology, Yenimahalle State Hospital, Ankara, Turkey \\ 2Department of Dermatology, Diskapı Research and Training Hospital, Ankara, Turkey \\ Head of the Department: Assist. Prof. Müzeyyen Gönül \\ ${ }^{3}$ Department of Dermatology, Numune Research and Training Hospital, Ankara, Turkey \\ Head of the Department: Prof. Dr. Ülker Gül \\ ${ }^{4}$ Department of Dermatology, Ağrı State Hospital, Ağrı, Turkey \\ ${ }^{5}$ Department of Dermatology, School of Medicine, Balikesir University, Balikesir, Turkey \\ Head of the Department: Arzu Kilic \\ ${ }^{6}$ Family Medicine, Kilis Public Health Research, Kilis, Turkey
}

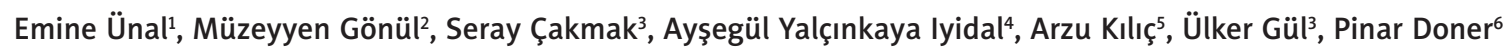

\begin{abstract}
Introduction: Human papillomavirus (HPV) is one of the most common causes of sexually transmitted diseases (STD). The incidence of condyloma acuminata (CA) has increased in recent years.

Aim: To determine demographical features and serological test results of STD in patients with CA.

Material and methods: A cross-sectional survey was conducted on 94 patients presenting to a dermatology clinic in Ankara, Middle Anatolia, Turkey. Dermatological examinations were made and the patients completed a questionnaire which consisted of questions about their marital status, partners and condom use. In all cases, VDRL/ RPR, anti-HIV, HBsAg, anti-HCV and in 57 cases - HSV type 1-2 IgM and IgG were studied. If the value of VDRL or RPR was positive, TPHA was conducted.

Results: In our study, 83 men and 11 women had CA. We could not analyze whether our cases had multiple partners and a habit of condom use as some of the patients did not answer questions about their sexual life. We observed VDRL and TPHA positivity in 3 (3.1\%) cases, none of those cases had clinical findings of syphilis and they denied using any therapy for syphilis. HBsAg positivity was found in 3 cases. No anti-HIV and anti-HCV antibody positivity was detected.

Conclusions: The seroprevalence of HBsAg in our study was similar to that of the general population of Turkey. But as we found positive syphilis serology in 3 patients, we suggest that syphilis serology should be investigated in patients with CA.
\end{abstract}

Key words: condyloma, syphilis, hepatitis B, HSV virology.

\section{Introduction}

Sexually transmitted diseases (STDs) are human immunodeficiency virus (HIV), human papillomavirus (HPV), syphilis and other infections. Infection with HPV is one of the most common STDs. Human papillomavirus can cause benign condylomas or malignant tumors depending on the type. Condyloma acuminata (CA) is a tumor-like lesion that is caused by most frequent HPV types 6 and 11. The worldwide prevalence of CA ranges from $5 \%$ to $20 \%$. Condyloma acuminatas are usually asymptomatic but affect patients' psychology and reduce the quality of their life [1-3]. Condyloma acuminata represents a major public health problem worldwide especially in developing countries [4-6]. It is known that if a patient has a STD, he has a risk of having other STDS [7-14]. In the literature there are few studies that investigate the relation between CA and other STDs [12-15].

\section{Aim}

In this study, we aimed to determine demographical features of patients with CA and serological test results of STD in patients with CA.

Address for correspondence: Emine Ünal, Department of Dermatology, Yenimahalle State Hospital, Ankara, Turkey, phone: +90 05309334337, fax: +90 03122553775, e-mail: eminesu83@gmail.com Received: 3.10.2014, accepted: 5.11.2014. 


\section{Material and methods}

Ninety-four patients (> 18 years old) were included in our study. Approval for the study was received from the Ankara Numune Education and Research Hospital Scientific Committee. Dermatological examinations of the patients were made and the patients completed a questionnaire which consisted of questions about their age, gender, marital status, partners and condom use. In all cases, Venereal Disease Research Laboratory (VDRL) or rapid plasma reagin (RPR), human immunodeficiency virus antibody (anti-HIV), hepatitis B antigen (HBsAg), anti-hepatitis C virus antibody (anti-HCV) and in 57 cases, herpes simplex virus type 1-2 immunoglobulin M (lg) and IgG were studied. If the value of VDRL or RPR was positive, Treponema pallidum hemagglutination assay (TPHA) was conducted for confirmation.

\section{Statistical analysis}

Data analysis was performed by using SPSS for Windows, version 11.5 (SPSS Inc., Chicago, IL, United States). Metric discrete variables were shown as mean \pm standard deviation (SD) or median (min.-max.), where applicable. While, the mean differences between the groups were compared by Student's $t$ test, Mann-Whitney $U$ test was applied for comparisons of the median values. Nominal data were analyzed by Fisher's exact test. A $p$ value less than 0.05 was considered statistically significant.

\section{Results}

In our study, 83 (88.3\%) men and 11 (11.7\%) women had CA. Demographical features of the patients and a habit of condom use are shown in Table 1.

No other STD was detected on dermatological examination.

We observed VDRL and TPHA positivity in 3 (3.1\%) cases. HBsAg positivity was found in 3 cases. No anti-HIV and anti-HCV antibody positivity was detected in any of the patients.

Herpes virus type 1 IgM was positive in 2 (3.5\%) and IgG was positive in 52 (91.2\%) cases. In patients who had herpes simplex virus (HSV) type 1 IgM positive, HSV type 1 IgG was also positive. But there were no active lesions. HSV type 2 IgG was positive in 6 (10.5\%) cases. HSV type 2 IgM was not detected in any of the patients (Table 1).

\section{Discussion}

Condylomas are benign lesions that may be located anywhere in the genital tract especially at the external genital area [1].

It is known that if a patient has a STD, he has a risk of having other STDs [7-14]. Especially when having an ulcer on the genitalia, it is easy to get another STD. It is believed that by early diagnosis and treatment of all STDs, HIV transmission can be reduced [7-14].
In the literature, there are few studies that investigated the relation between CA and other STDs. Smith et al. studied HIV serology in HPV-positive men, and they found high HIV positivity and suggested that HPV prevention could be useful for HIV prevention [12].

Kavak et al. investigated the coincidence between some of the STDs and hepatitis B, C and HIV infections in 1998-2001. Among 50 patients who had been included in this study, CA was found in 26 (52\%) patients, syphilis (7 latent, 2 secondary) in 9 (18\%), non-gonococcal urethritis in 5 (10\%), molluscum contagiosum in 4 (8\%), gonorrhea in $3(6 \%)$ and herpes genitalis in $3(6 \%)$ patients. In this study, in all cases, only HBsAg, anti-HBs, anti-HBc, anti-HIV, anti-HCV had been studied. HBsAg positivity had been found in 4 (8\%) cases. They compared the results with the control group and this positivity was found similar to the control group. They found anti-HBC positivity significantly higher in the STDs group. There were no positive results for anti-HIV and anti-HCV [13].

In the study by Kaymak et al. in 2004, 50 patients who were diagnosed with CA were investigated for coincidence with other STDs. Thirty-six males and 14 females had been included in this study. The male/female ratio was 2.5. In all cases, VDRL, TPHA, HBsAg, anti-HBs, anti-HCV and anti-HIV had been studied. They also investigated risk factors for multiple infections. They found other STDs in 13 patients: 3 tinea inguinalis, 1 genital herpes infection, 2 syphilis (secondary), 1 gonorrhea, 1 scabies, 1 vaginal candidiasis, and 2 trichomonas vaginalis [14].

Dolar et al. investigated the prevalence of HSV-1 and HSV 2 in selected populations of adults, pregnant wom-

Table 1. Demographical features and serological test results of the patients $(n=94)$

\begin{tabular}{lc}
\hline Variables & Results \\
\hline Age, mean \pm SD [year] & $34.9 \pm 10.2$ \\
\hline Age, range [year] & $18-61$ \\
\hline Gender, $n$ (\%): & $83(88.3)$ \\
\hline Male & $11(11.7)$ \\
\hline Female & $57(60.6)$ \\
\hline Marital status, $n(\%):$ & $34(36.2)$ \\
\hline Married & $3(3.2)$ \\
\hline Single & $21(22.3)$ \\
\hline Widows/widowers & $3(3.2)$ \\
\hline Condom use, $n(\%)$ & $3(3.2)$ \\
\hline VDRL, $n(\%)$ & $6(6.4)$ \\
\hline HBaAG, $n(\%)$ & $2(2.1)$ \\
\hline Type, $N=57, n(\%):$ & $52(55.3)$ \\
\hline I IgM & \\
\hline I IgG & \\
\hline II gG & \\
\hline
\end{tabular}


en, blood donors, sex workers and patients who were diagnosed with CA, in Turkey. In this study, 2082 patients' sera were sampled and in 110 out of 2082 CA had been diagnosed. In all patients, HSV-1 and HSV-2 IgG were studied [15].

Our study included more patients (94 patients) than previous studies that were performed on CA patients. In all cases, VDRL or rapid plasma reagin (RPR), anti-HIV, HBsAg, anti-HCV and in 57 cases, HSV type 1-2 lgM and IgG were studied. Our study was conducted with wider parameters than the 3 other studies performed in Turkey. Condyloma acuminata was seen in 83 (88.3\%) men and in $11(11.7 \%)$ women in our study. The male/female ratio (7.3) was higher in our study than in the study that had been performed in Turkey by Kaymak et al. (2.5) [14].

The average age of CA was $34.9 \pm 10.2 ; 35 \pm 10.2$ in men and $33.5 \pm 10.9$ in women. The average age of CA in our study was similar to that reported in the literature in our country $[13,14]$.

The number of warts ranged between 1 and 52. The median number of warts was 7 in all patients: 8 in men and 3 in women. We could not reach any study which recorded the number of anogenital warts and because of this, we could not compare the number of warts.

HBV infection is one of the STDS. HBsAg prevalence appears to differ considerably in different ages and in various parts of Turkey. The prevalence of HBsAg ranges between $2.8 \%$ and $6 \%$ according to the reports, in Turkey [16-18]. HBsAg positivity was found in 3 (3.2\%) cases in our study. The seroprevalence of HBsAg in our study was similar to that in the general population of Turkey but lower than in the study by Kavak et al. (8\%) [13]. This finding may be related to the vaccination program in children launched after 2001.

We observed VDRL and TPHA positivity in 3 (3.1\%) cases. None of those cases had clinical findings of syphilis and they denied any therapy for syphilis. 2 of them were married and one was single but all of them had multiple partners (more than two). Their ages were 26, 41 and 60 . None of them used condoms. None of them had a systemic disorder and drug use. In all patients, serologic tests for hepatitis and HIV were negative. We treated the patients with penicillin. In the study presented by Kaymak et al., they had observed 2 (4\%) patients with syphilis [14].

The results about sexual transmission of HCV infection are conflicting. Neumayr et al. reported that if a partner had HCV infection, the risk to infect their partner was only 2.5\% [19]. Another study conducted by Ozer et al. found that anti-HCV positivity was higher in married patients [20]. The seroprevalence of HCV in smaller groups in different parts of Turkey was shown to range between 0 and 3.9\% [21]. In our study, anti-HCV antibody positivity was not detected in any of the patients like in the studies reported by Kavak et al. and Kaymak et al. [13, 14].
HIV infection and immunosuppression facilitate HPV infection. Silverberg et al. studied HPV 6 and 11 frequency in HIV-positive and HIV-negative women. They found that HPV 6-11 frequency was higher in HIV-positive women than in HIV-negative ones [22]. In our study, anti-HIV positivity was not detected in any of the patients. In the studies reported by Kavak et al. and Kaymak et al., there was no anti-HIV positivity $[13,14]$.

Infection with HSV is widespread in many parts of the world. It is important that several STDs including HSV-2 have been reported with HPV in the etiology of cervical cancer $[23,24]$. HSV causes genital ulcer and this ulcer is associated with an increased susceptibility to other STDs $[10,25]$. In spite of the large prevalence of HSV infection, relatively few data have been published regarding the seroprevalence of HSV infection in the literature. Herpes virus type 1 IgM was positive in 2 (3.5\%) and IgG was positive in 52 (91.2\%) cases in our study. In patients who had HSV type 1 IgM positive, HSV type 1 IgG was also positive. But there were no active lesions. HSV type 1 lgG positivity was found in $91.2 \%$ in our study, this ratio was similar to that in the study presented by Dolar et al. in Istanbul (93.6\%) [15].

HSV type $2 \mathrm{lgM}$ was not detected any of the patients. HSV type 2 lgG was positive in 6 (10.5\%) patients who had CA in our study and this positivity was lower than in the study presented by Dolar et al. in Istanbul (17.3\%). It may be related to the difference in sexual behaviors between Ankara and Istanbul.

In the study presented by Dolar et al., the prevalence of HSV-2 antibodies was $4.8 \%$ in sexually active adults [15]. This positivity shows that the seroprevalence of HSV infection was higher in patients with CA. In the study presented by Kaymak et al. [14], only 1 case had active genital herpes and they did not study serology of the HSV. In our study, we did not detect any active genital herpes infection.

\section{Conclusions}

Consequently, we found positive syphilis serology in 3 patients with CA although serology of other STDs was not increased in CA patients. We suggest that syphilis serology should be investigated in patients with CA because it is a very important disease for both the patient and the general community health.

\section{Acknowledgments}

This research was conducted at the Numune Research and Training Hospital, Department of Dermatology, Ankara, Turkey.

\section{Conflict of interest}

The authors declare no conflict of interest. 


\section{References}

1. Cardoso JC, Calonje E. Cutaneous manifestations of human papillomaviruses: a review. Acta Dermatovenerol Alp Panonica Adriat 2011; 20: 145-54.

2. Steben M, LaBelle D. Genital warts: Canadians' perception, health-related behaviors, and treatment preferences. I Low Genit Tract Dis 2012; 16: 409-15.

3. Mortensen GL, Larsen HK. The quality of life of patients with genital warts: a qualitative study. BMC Public Health 2010; 10: 113.

4. Baandrup L, Blomberg M, Dehlendorff C, et al. Significant decrease in the incidence of genital warts in young Danish women after implementation of a national human papillomavirus vaccination program. Sex Transm Dis 2013; 40: 130-35.

5. Marlow LA, Zimet GD, McCaffery KJ, et al. Knowledge of human papillomavirus (HPV) and HPV vaccination: an international comparison. Vaccine 2013; 31: 763-9.

6. Mikolajczyk RT, Kraut AA, Horn J, et al. Changes in incidence of anogenital warts diagnoses after the introduction of human papillomavirus vaccination in Germany - an ecologic study. Sex Transm Dis 2013; 40: 28-31.

7. Sciarra JJ. Sexually transmitted diseases: global importance. Int J Gynaecol Obstet 1997; 58: 107-19.

8. Finan RR, Musharrafieh U, Almawi WY. Detection of Chlamydia trachomatis and herpes simplex virus type 1 or 2 in cervical samples in human papilloma virus (HPV)-positive and HPV-negative women. Clin Microbiol Infect 2006; 12: 927-30.

9. Lee KH, Ho TS, Shen CF, et al. Clinical and laboratory characteristics of human immunodeficiency virus-infected adolescents: experience from a single medical center. J Microbiol Immunol Infect 2012; 45: 329-36.

10. Czelusta A, Yen-Moore A, Van der Straten M, et al. An overview of sexually transmitted diseases. Part III. Sexually transmitted diseases in HIV-infected patients. J Am Acad Dermatol 2000; 43: 409-32.

11. Munk C, Nielsen A, Liaw KL,et al. Genital warts in men: a large population-based cross-sectional survey of Danish men. Sex Transm Infect 2012; 88: 640-4.

12. Smith JS, Moses S, Hudgens MG, et al. Increased risk of HIV acquisition among Kenyan men with human papillomavirus infection. J Infect Dis 2010; 201: 1677-85.

13. Kavak A, Parlak A, Akman R, et al. An evaluation of hepatitis $B, C$ and HIV infections in sexually transmitted diseases. Turk Derm 2002; 36: 272-5.

14. Kaymak Y, Yüksel N, Eksioglu M. Coincidence of condyloma accuminata with other sexually transmitted diseases. Turk Derm 2004; 38: 48-53.

15. Dolar N, Serdaroglu S, Yilmaz G, et al. Seroprevalence of herpes simplex virus type 1 and type 2 in Turkey. J Eur Acad Dermatol Venereol 2006; 20: 1232-6.

16. Ergunay K, Balaban Y, Cosgun E, et al. Epidemiologic trends in HBV infections at a reference centre in Turkey: an 11-year retrospective analysis. Ann Hepatol 2012; 11: 672-8.

17. Altay T, Uskun E, Akcam FZ. Seroprevalence of hepatitis B surface antigen and its correlation with risk factors among new recruits in Turkey. Braz J Infect Dis 2012; 16: 339-44.

18. Toy M, Onder FO, Wormann T, et al. Age- and region-specific hepatitis B prevalence in Turkey estimated using generalized linear mixed models: a systematic review. BMC Infect Dis 2011; 11: 337.

19. Neumayr G, Propst A, Schwaighofer H, et al. Lack of evidence for the heterosexual transmission of hepatitis C. QJM 1999; 92: 505-8.
20. Ozer B, Seydaoglu G, Ozsahin AK, et al. Risk factors for higher anti-HCV positivity in a border city in southern Turkey with unique population characteristics. Turk J Gastroenterol 2012; 23: 574-9.

21. Mıstık R, Balık I. Epidemiological analyses of viral hepatitis in Turkey. In: Tekeli E, Balık I (eds). Viral hepatitis. Epidemiological analyses of viral hepatitis in Turkey 2003, Ankara 2003; 9-55.

22. Silverberg MJ, Ahdieh L, Munoz A, et al. The impact of HIV infection and immunodeficiency on human papillomavirus type 6 or 11 infection and on genital warts. Sex Transm Dis 2002; 29: 427-35.

23. Arnheim Dahlstrom L, Andersson K, Luostarinen T, et al. Prospective seroepidemiologic study of human papillomavirus and other risk factors in cervical cancer. Cancer Epidemiol Biomarkers Prev 2011; 20: 2541-50.

24. Smith JS, Herrero R, Bosetti C, et al. Herpes simplex virus-2 as a human papillomavirus cofactor in the etiology of invasive cervical cancer. J Natl Cancer Inst 2002; 94: 1604-13.

25. McClelland RS, Wang CC, Overbaugh J, et al. Association between cervical shedding of herpes simplex virus and HIV-1. AIDS 2002; 16: 2425-30. 